\title{
Outcome of corneal transplantation in a private institution in Saudi Arabia
}

This article was published in the following Dove Press journal:

Clinical Ophthalmology

27 June 2013

Number of times this article has been viewed

\author{
Nazri Omar ${ }^{1,2}$ \\ Charbel T Bou Chacra ${ }^{1}$ \\ Khalid F Tabbara ${ }^{1,3,4}$ \\ 'The Eye Center and The Eye \\ Foundation for Research in \\ Ophthalmology, Riyadh, Saudi Arabia; \\ ${ }^{2}$ Department of Ophthalmology, \\ Universiti Putra Malaysia, \\ Serdang, Malaysia; ${ }^{3}$ Department of \\ Ophthalmology, King Saud University, \\ Riyadh, Saudi Arabia; ${ }^{4}$ The Wilmer \\ Ophthalmological Institute \\ of Johns Hopkins University School \\ of Medicine, Baltimore, MD, USA
}

Background: The aim of this work was to describe the indications, complications, and outcomes of penetrating keratoplasty (PKP) in Saudi Arabia.

Methods: In a retrospective, noncomparative interventional case series, the medical records of patients who underwent PKP from January 2000 to December 2008 and had a minimum follow-up of 6 months were reviewed. All corneas were obtained from eye banks in the US. Indications, complications, and outcomes of surgery were recorded. This study was approved by the institutional review board.

Results: Eighty-five consecutive eyes were included in this study. There were $52(61.2 \%)$ males and 33 (38.8\%) females. The median age was 35.0 years (range 3-85 years), and the median follow-up period was 24 months (range 6-108 months). The indications for PKP were keratoconus, bullous keratopathy, corneal scars, corneal dystrophy, and corneal regraft. The overall graft survival time was 88.9 months \pm 4.9 months (mean \pm standard error of mean, 95\% confidence interval [CI] 79.4 months -98.4 months) while the 3-year and 5-year cumulative survival rates were $90.7 \%$ and $84.3 \%$, respectively. Surgical indication $(P=0.038)$, immune rejection $(P<0.001)$, preoperative corneal vascularization $(P=0.022)$, and perioperative high intraocular pressure $(P=0.032)$ were associated significantly with corneal graft failure in univariate analysis. Multivariate analysis reduced these significant associations to rejection $(P<0.001)$ and vascularization $(P=0.009)$. Relative risk for failure in rejected cornea was 16.22 (95\% CI 4.99-52.69) and in vascularized cornea was 3.89 (95\% CI 1.36-11.09). At last visit following PKP, 34 (40\%) eyes had best spectacle-corrected visual acuity of 20/40 or better, and $51(60.0 \%)$ eyes had 20/80 or better. Best spectacle-corrected visual acuity was worse than $20 / 400$ in $15(17.6 \%)$ eyes.

Conclusion: The overall corneal graft survival in a private setting in Saudi Arabia can be excellent. Thorough preoperative evaluation and comprehensive postoperative management are crucial for successful corneal transplantation. A larger multicenter study is recommended to portray the outcome of private corneal transplantation in Saudi Arabia in general.

Keywords: cornea, corneal transplantation, corneal dystrophy, corneal scars, bullous keratopathy, keratoconus, herpetic keratitis

\section{Introduction}

Ever since the first successful human full-thickness corneal transplant, or penetrating keratoplasty (PKP), by Eduard Zirm in 1906, ${ }^{1,2}$ it has been regarded as one of the most frequently performed tissue transplantations in humans. ${ }^{3,4}$ It has also enjoyed a relatively high success rate. ${ }^{5,6}$ Improvement in instrumentation and surgical techniques, systematic and efficient tissue banking, and better postoperative management that includes antiinflammatory and immunosuppressive drugs ${ }^{7-10}$ have collectively improved corneal 
transplant outcome. ${ }^{11}$ This has led to the extension of indications for performing PKP to encompass high-risk eyes, such as vascularized cornea and previously failed corneal graft. ${ }^{12-14}$ However, these indications were shown to be associated with a lower rate of graft survival. ${ }^{12}$

Several reviews of corneal transplant revealed, not only that indications for PKP have changed, but also that keratoplasty techniques have also evolved. ${ }^{15-18}$ Although there was a decrease in the number of PKPs performed over the last decade in favor of lamellar keratoplasty for selected indications, PKP remained the most frequently indicated type of corneal transplant. ${ }^{15,19}$ As such, continuous efforts to understand issues related to graft survival in PKP will continue to be of high relevance in the field of transplant immunology, especially in developing countries.

In Saudi Arabia, several reports on patient profiles, surgical indications, complications, and outcomes of PKP performed by multiple surgeons in public hospitals have been published. ${ }^{20-24}$ In contrast, such data from a private institution are a rarity. To the best of our knowledge, this report represents the first published PKP data by a single surgeon in a private ophthalmic institution in Saudi Arabia. Furthermore, the prevalent dry-eye issue ${ }^{25}$ poses an additional challenge in the treatment for PKP in developing countries with hot, arid desert environments such as Saudi Arabia. It demands a closer follow-up regime, which might more likely be achieved in the private setting. Therefore, this study was of particular importance, as it allowed us to understand the outcomes following PKP in a private institution with no intersurgeon bias and with a closer follow-up system. This would eventually lead to better patient selection, surgical performance, and postoperative management. As such, the best possible result can be hoped for and practically achieved.

\section{Patients and methods \\ Patients}

This study was a retrospective, uncontrolled interventional case series. After obtaining the approval from the institutional review board, medical records of every patient who underwent PKP at the Eye Center, Riyadh, Saudi Arabia from January 2000 to December 2008 were reviewed. All cases with follow-up for at least 6 months were included. In order to accommodate for the possibility of primary graft failure, all failed corneal grafts were included regardless of their follow-up period. Epidemiological data, indication for PKP, surgical profile, and the outcome were recorded. We certify that all applicable institutional and governmental regulations concerning the ethical use of human volunteers were complied with during this research.

All surgical procedures were performed on an inpatient basis by a single senior consultant ophthalmic surgeon. Donor corneal tissues were entirely obtained from eye banks in the US that were accredited members of the Eye Bank Association of America. All recipient corneas were sent for histopathologic analysis to confirm the clinical diagnosis, and the donor corneal rims were subjected to culture and sensitivity tests.

\section{Surgical procedures and follow-up}

The PKP surgeries were performed under general anesthesia. After preparing the recipient eye, the corneal donor buttons were prepared using manual trephine. The suture techniques used were either continuous 11-0 nylon or interrupted 10-0 nylon, or a combination of both techniques. The operated eyes were padded and shielded until the first eye dressing, usually carried out on the following day.

Following PKP, patients were evaluated daily for the first 3 days or until re-epithelialization had completed and patients were discharged from the ward. The patients were later examined at 1 week and at 1, 3, 6, 9, 12, 18, and 24 months from the date of surgery, and every 6 months thereafter. In the absence of suspicion for infection, postoperative treatment for patients with keratoconus, bullous keratopathy, and corneal dystrophy consisted of topical corticosteroid (prednisolone acetate 1\%) which was administered every 2 hours for 1 week, followed by 6-hourly for 4 weeks and 12-hourly for 3 months. Patients were then maintained on one drop of steroid daily until sutures were removed, which took place after refraction at 1 year postoperatively.

Patients with preoperative herpetic keratitis received prophylactic systemic and topical antiviral drugs before and after surgery. Oral antiviral in the form of valacyclovir $500 \mathrm{mg}$ twice daily was discontinued 2 weeks after surgery. Patients were then maintained on topical ganciclovir $0.15 \%$ ophthalmic gel (Virgan; Laboratoires Théa, Claremont-Ferrand, France) once daily for 1 month followed by twice-weekly for a period of 2 years after the surgery. ${ }^{26}$ All patients were given topical prophylactic antibiotics in the form of third- or fourth-generation quinolone for 1 month.

Patients with vascularized corneas were given subTenon's injection of triamcinolone acetate $40 \mathrm{mg}$ at the conclusion of surgery and kept on topical prednisolone acetate $1 \%$ eye drops every 2 hours for a period of 1 week, followed by 6-hourly for 4 weeks and 12-hourly for 3 months. Patients were then maintained on one drop of steroid daily until sutures were removed at 1 year. Loose or infected 
sutures were removed immediately with appropriate coverage of steroids, antibiotics, or a combination of both.

\section{Follow-up retrieval system}

A couple of days before their scheduled appointment, the patients were called to remind them of their appointments. In the event of failure to attend the follow-up examination, the patients were called again and an earliest new appointment convenient for the patients was set.

\section{Clinical data management}

Data extracted included patients' reference number, age, sex, laterality, postoperative follow-up period, surgical indication, and presence of vascularization, defined as presence of at least a blood vessel extending more than $3 \mathrm{~mm}$ from the limbus. The surgical variables assessed were suture techniques used and concurrent procedures performed. Postoperative complications examined were persistent epithelial defect, corneal graft rejection, PKPrelated infection, and glaucoma deterioration. Outcome of surgery was represented by best spectacle-corrected visual acuity (BSCVA) and presence of graft failure during last follow-up visit.

\section{Statistical analyses}

Data were analyzed using SPSS 17.0 (IBM, Armonk, NY, USA). Potential predictors of graft failure were determined using univariate and multivariate regression analysis. The Spearman chi-squared test was used for categorical data and Wilcoxon ranks test was used to compare pre- and postoperative logarithm of minimum angle of resolution (logMAR) BSCVA. Survival analysis using the Kaplan-Meier model was performed to determine the overall corneal graft survival time and probability. Log-rank (Mantel-Cox) tests were used to determine the difference of survival between the strata. $P$-values of less than 0.05 were considered statistically significant.

\section{Results}

\section{Patient characteristics}

Eighty-five consecutive PKP surgeries performed during the study period were included. No case was excluded, as all had a follow-up period of more than 6 months and there was no graft failure occurring less than 6 months after surgery. There were 52 (64.3\%) males and 33 (35.7\%) females. Age ranged from 3 to 85 years, with a median age of 35 years. The follow-up period ranged from 6 to 108 months, and the median was 24 months.

\section{Corneal graft failure}

Graft failure was encountered in eleven (12.9\%) of 85 eyes. The overall survival time for corneal graft in this study was 88.9 months \pm 4.9 months (mean \pm standard error of mean, 95\% confidence interval [CI] 79.4 months -98.4 months). The projected 3-year and 5-year cumulative survival rates were $90.7 \%$ and $84.3 \%$, respectively (Figure 1).

\section{Corneal graft-failure association}

Univariate analysis revealed age-group $(P=0.291)$, sex $(P=0.132)$, side of eye operated on $(P=0.753)$, concurrent surgical procedure $(P=0.702)$, suturing technique $(P=0.316)$, and infection $(P=0.062)$ had no statistically significant association with corneal graft failure. On the other hand, surgical indication $(P=0.038)$, corneal graft rejection $(P<0.001)$, preoperative corneal vascularization $(P=0.022)$, and perioperative raised intraocular pressure (IOP) $(P=0.032)$ were found to have statistically significant associations with corneal graft failure (Table 1).

The majority of the infected cases were elderly patients (more than 60 years, seven cases, 87.5\%) and male (six cases, $75.0 \%$ ). In terms of surgical indication for PKP, no indication was spared except keratoconus. Suture-related infection was encountered in three $(37.5 \%)$ cases, and infected ulcer in the remaining five $(62.5 \%)$ cases. Microbiological investigation was performed in seven cases. Culture was positive in five (71.4\%) out of seven cases. Among the culture-positive infections, Gram-positive bacteria in the form of Staphylococcus

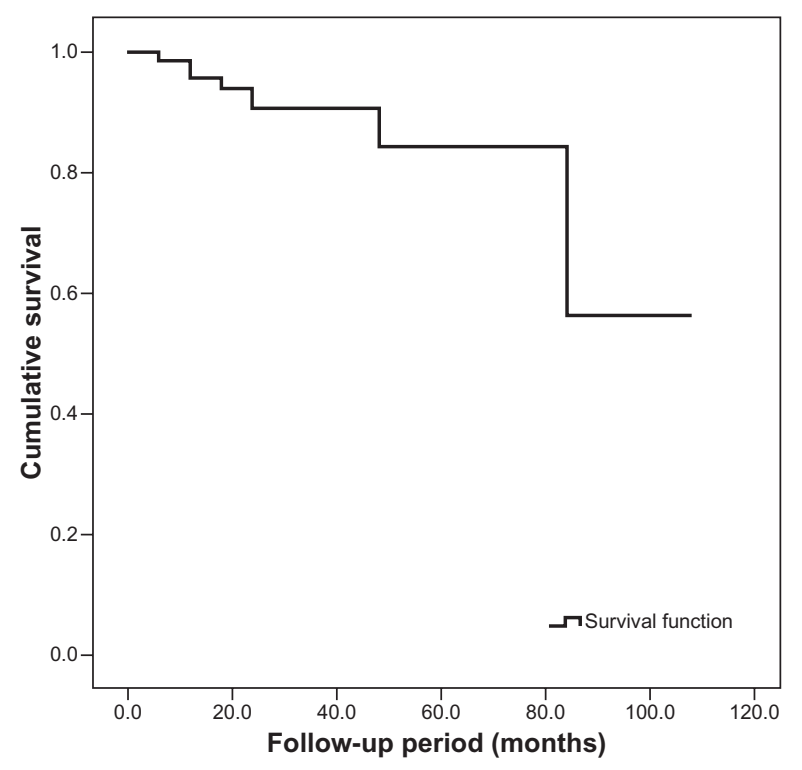

Figure I Kaplan-Meier survival curve for corneal graft following penetrating keratoplasty. The overall survival time was 88.9 months \pm 4.9 months (mean \pm standard error of mean, $95 \%$ confidence interval 79.4 months -98.4 months). 
Table I Univariate analysis of graft failure association $(P<0.05$ indicates statistical significance)

\begin{tabular}{|c|c|c|c|}
\hline $\begin{array}{l}\text { Factors associated with } \\
\text { corneal graft failure } \\
(\text { total eyes }=85)\end{array}$ & n (\%) & $\begin{array}{l}\text { Failed grafts } \\
\text { (\%) }\end{array}$ & $P$-value \\
\hline Age-group & & & 0.291 \\
\hline 20 years and less & $15(17.6)$ & I (6.7) & \\
\hline 21 to 40 years & $31(36.5)$ & $2(6.5)$ & \\
\hline 41 to 60 years & II (I2.9) & $2(18.2)$ & \\
\hline Above 60 years & $28(32.9)$ & $6(2 \mid .4)$ & \\
\hline Sex & & & 0.132 \\
\hline Male & $52(61.2)$ & $9(17.3)$ & \\
\hline Female & $33(38.8)$ & $2(6.1)$ & \\
\hline Side & & & 0.753 \\
\hline Right & $49(57.6)$ & $7(14.3)$ & \\
\hline Left & $36(42.4)$ & $4(I I . I)$ & \\
\hline Surgery & & & 0.702 \\
\hline PKP only & $61(71.8)$ & $7(I I .5)$ & \\
\hline $\begin{array}{l}\text { PKP with cataract surgery, } \\
\text { IOL }\end{array}$ & $20(23.5)$ & $3(15.0)$ & \\
\hline PKP with IOL implantation & $4(4.7)$ & I (4.3) & \\
\hline Suturing technique & & & 0.316 \\
\hline Interrupted only & $\mathrm{I}(\mathrm{I} .2)$ & $0(0)$ & \\
\hline Combined & $60(70.6)$ & $10(16.4)$ & \\
\hline Double continuous & $24(28.3)$ & I (4.3) & \\
\hline Indication & & & 0.038 \\
\hline Keratoconus & $33(38.8)$ & $2(6.1)$ & \\
\hline Scar & $15(17.6)$ & I (6.7) & \\
\hline Bullous keratopathy & $11(12.9)$ & $3(27.3)$ & \\
\hline Regraft & $10(11.8)$ & $4(40.0)$ & \\
\hline Corneal dystrophy & $16(18.8)$ & $\mathrm{I}(6.3)$ & \\
\hline Rejection & $12(14.1)$ & $8(66.7)$ & $<0.001$ \\
\hline Vascularization & $15(17.6)$ & $5(33.3)$ & 0.022 \\
\hline Infection & $8(9.4)$ & $3(37.5)$ & 0.062 \\
\hline Raised intraocular pressure & & & 0.032 \\
\hline No glaucoma & $44(5 \mathrm{I} .8)$ & $4(9.1)$ & \\
\hline Preexisting glaucoma & $10(11.8)$ & $4(40.0)$ & \\
\hline Steroid responder & $11(12.9)$ & $0(0)$ & \\
\hline Other & $20(23.5)$ & $3(15.0)$ & \\
\hline
\end{tabular}

Abbreviations: PKP, penetrating keratoplasty; IOL, intraocular lens.

epidermidis (two cases, 40\%), Streptococcus species (two cases, 40\%), and Candida albicans (one case, 20\%) were isolated. All cases responded to appropriate topical antimicrobial treatment.

Multivariate analysis was conducted, and revealed only rejection $(P<0.001)$ and corneal vascularization $(P=0.009)$ had statistically significant associations with corneal graft failure, but neither raised IOP $(P=0.962)$ or surgical indication $(P=0.741)$. Regression analysis and graft survival for comparison of strata within rejection and vascularization factors were performed. Risk for graft failure increased by 16 -fold if there was rejection (relative risk $=16.22,95 \%$ CI 4.99-52.69), and by almost fourfold in vascularized cornea (relative risk $=3.89$, 95\% CI 1.36-11.09). From the Kaplan-Meier model, it was revealed that grafts with rejection had shorter
Table 2 Comparison of corneal graft survival time between strata in rejection, vascularization, and surgical indication factors $(P<0.05$ indicates statistical significance $)$

\begin{tabular}{|c|c|c|c|c|c|}
\hline \multirow[t]{2}{*}{ Factor } & \multirow{2}{*}{$\begin{array}{l}\text { Survival time } \\
\text { (months) } \\
\text { Mean } \pm \text { SD }\end{array}$} & \multicolumn{2}{|l|}{$95 \% \mathrm{Cl}$} & \multicolumn{2}{|c|}{$\begin{array}{l}\text { Log-rank } \\
\text { (Mantel-Cox) }\end{array}$} \\
\hline & & Lower & Upper & $\lambda^{2}$ & $P$ \\
\hline \multicolumn{6}{|l|}{ Rejection } \\
\hline None & $100.5 \pm 3.9$ & 92.8 & 100.1 & 31.13 & $<0.001$ \\
\hline Present & $46.8 \pm 9.5$ & 28.2 & 65.3 & & \\
\hline \multicolumn{6}{|l|}{ Vascularization } \\
\hline None & $94.6 \pm 4.9$ & 85.0 & 104.3 & 4.570 & 0.033 \\
\hline Present & $63.4 \pm 9.0$ & 45.6 & 81.1 & & \\
\hline \multicolumn{6}{|c|}{ Surgical indication } \\
\hline $\begin{array}{l}\text { Bullous } \\
\text { keratopathy }\end{array}$ & $68.1 \pm 12.3$ & 44.1 & 92.1 & 8.016 & 0.091 \\
\hline Keratoconus & $88.6 \pm 4.8$ & 79.2 & 98.0 & & \\
\hline $\begin{array}{l}\text { Corneal } \\
\text { dystrophy }\end{array}$ & $101.1 \pm 6.6$ & 88.2 & II4.I & & \\
\hline Regraft & $68.3 \pm 11.2$ & 46.4 & 90.1 & & \\
\hline Corneal scar & $55.5 \pm 4.2$ & 47.3 & 63.7 & & \\
\hline Raised IOP* & & & & & \\
\hline
\end{tabular}

Note: *Not computable, as all cases were censored in one strata.

Abbreviations: $\mathrm{Cl}$, confidence interval; SD, standard deviation; IOP, intraocular pressure.

mean survival time compared to grafts without rejection. Likewise, grafts in vascularized corneas had shorter mean survival time compared to grafts in nonvascularized corneas (Table 2). In line with these findings, the 3-year and 5-year survival rates of grafts with rejection and vascularization were also reduced when compared to survival of corneal grafts without rejection and vascularization (Figure 2).

\section{Outcome measures}

Distribution of the eyes with regard to the preoperative and postoperative $\log$ MAR BSCVA is depicted in Figure 3. BSCVA improvement was seen following PKP in 71 (83.5\%) eyes, unchanged in nine $(10.6 \%)$ eyes, and worsened in five $(5.9 \%)$ eyes. There was a statistically significant improvement in the vision from median preoperative logMAR of 2.0 (Snellen equivalent to finger-counting) to median postoperative logMAR 0.5 (Snellen equivalent to 20/60) $(Z=6.508, P<0.001)$. At latest follow up, $34(40 \%)$ eyes had Snellen BSCVA of 20/40 or better, $51(60.0 \%)$ had BSCVA of $20 / 80$ or better. BSCVA was worse than 20/400 in $15(17.6 \%)$ eyes.

\section{Discussion}

Although PKP has been among the most successful tissue transplantations in humans, outcomes may vary between different cohorts. This study provides important information about the indications and outcome of PKP in a private 

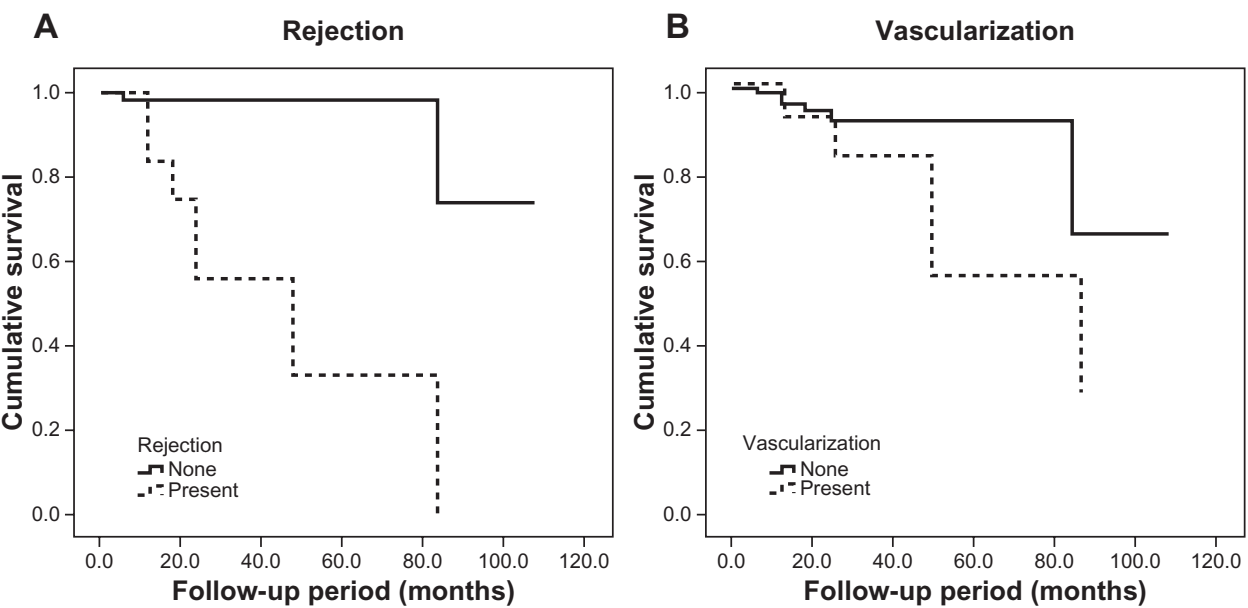

Figure 2 Kaplan-Meier survival curves for $(\mathbf{A})$ rejection (log-rank test, $\left.\lambda^{2}=31.13, P<0.001\right)$ and $(\mathbf{B})$ vascularization $\left(\log\right.$-rank test, $\left.\lambda^{2}=4.57, P=0.033\right)$.

healthcare facility, which may have patients of higher socioeconomic profile compared to public hospitals. Furthermore, wide accessibility, close follow-up and thorough surveillance in the private center were available to every patient. As comparison, appointments could be relatively longer and close follow-ups were generally limited in the public hospitals. In addition, the region where this study was conducted is characterized by a hot and arid desert climate. Such a climate may compromise the ocular surface and aggravate ocular conditions like dry-eye syndrome. Patients often required frequent lubrication, and this made the postoperative management of PKP patients more challenging than in other regions.

In our study, the indications for PKP, in order of decreasing frequency, were keratoconus (38.8\%), corneal dystrophy (18.8\%), corneal scar (17.6\%), bullous keratopathy (12.9\%), and regraft (11.8\%). Wagoner et a ${ }^{22,27}$ reported keratoconus (51.2\%), corneal edema (20.3\%), and scar (19.3\%) as the indications with highest frequency in a PKP series in a

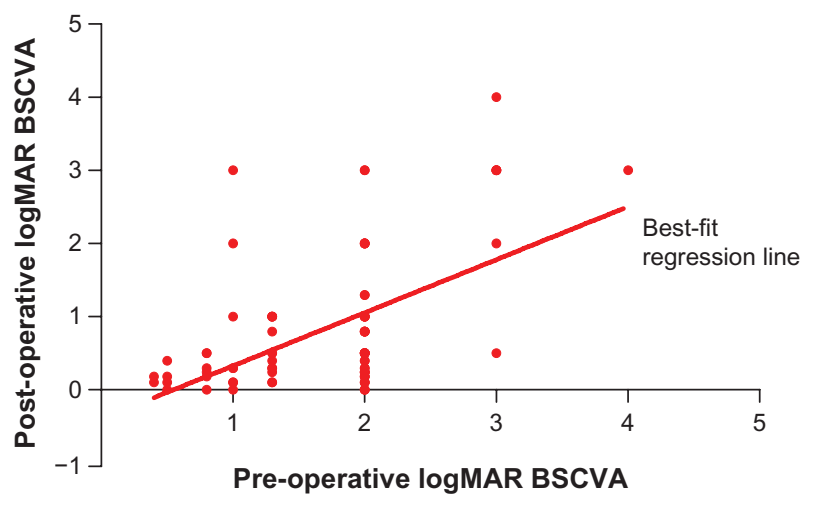

Figure 3 Distribution of eyes according to the pre-operative and post-operative logarithm of minimum angle of resolution (logMAR) best spectacle-corrected visual acuity (BSCVA) (slope $=0.73 \pm 0.12,95 \%$ confidence interval 0.48-0.97). public hospital in Saudi Arabia. Tan et a ${ }^{28}$ reported bullous keratopathy (23.4\%) and corneal scar (12.9\%) as the main indications for PKP in Singapore. Fasolo et a ${ }^{29}$ reported keratoconus (47\%), regraft (14\%), and bullous keratopathy $(14 \%)$ as the main indications for PKP in Italy. Sheldon et $\mathrm{l}^{30}$ reported failed graft (21\%), bullous keratopathy (20\%), and keratoconus as their most frequent indications for PKP. The observable difference and variation in PKP indications and outcomes in different countries are interesting. Many factors may play a role, including the climate, types of surgical procedures, prevalence of coexisting ocular surface disorders, and certain genetically determined tissue antigens. ${ }^{31}$

The 3-year and 5-year graft survival rates for our cohort were $90.7 \%$ and $84.3 \%$, respectively (Figure 1). These findings were comparable to the survival rates reported by other authors. Wagoner et $\mathrm{al}^{24}$ showed $86.0 \%$ and $80.3 \%$ survival at 3- and 5-year follow-ups, respectively. Fasolo et al $^{32}$ reported probability of 5 -year survival as $83 \%$ in their study. With longer follow-up, Thompson et al ${ }^{6}$ reported graft survival to be $90 \%$ and $82 \%$ at 5 and 10 years following PKP.

Surgical indication was recorded by Wagoner et $\mathrm{al}^{22}$ as the most significant risk factor affecting corneal graft survival. In contrast to their findings, we found that surgical indication was significantly associated with graft failure only in univariate analysis. It was also found that there was no significant difference in survival time between surgical indication strata. Certain surgical indications, such as corneal scarring and regraft, would have had vascularization, which actually contributed to the failure rate in these groups. We assessed that a larger sample size with longer follow-up would be necessary to resolve this issue. Having mentioned this, one has to bear in mind that the patients' profiles and indications 
for PKP may change with time, and these influence surgical outcome and graft survival. ${ }^{33}$

This study revealed corneal graft rejection occurred in twelve $(14.1 \%)$ of 85 eyes. Wagoner et $\mathrm{al}^{22}$ reported endothelial rejection as the most common complication (17.3\%) following primary adult PKP. Yalniz-Akkaya ${ }^{34}$ et al reported allograft rejection in $14.7 \%$ of eyes with primary corneal graft. In all these studies, immune rejection was significantly associated with graft failure. Immune rejection may result from loss of anterior chamber-associated immune deviation, which together with corneal avascularity and absence of corneal lymphatics partly confers immune privilege to the cornea and therefore is associated with graft failure. ${ }^{8}$ Our study also showed that corneal vascularization was significantly associated with a higher rate of corneal graft failure, both in univariate and multivariate analyses. Inoue et $\mathrm{al}^{35}$ reported that the relative risk of corneal graft failure increased from 1.67 in cornea with one quadrant vascularized to 3.39 in cornea with three or more quadrants vascularized. Price et $\mathrm{al}^{5}$ also reported that deep stromal vascularization had been identified as significantly associated with corneal graft failure in their study. Being vascularized, donor corneas could be exposed to the host immune system, which then triggers an inflammatory cascade leading to graft failure.

The graft failure rate was found to be significantly higher in eyes with raised IOP compared to eyes with normal IOP. ${ }^{36}$ Our series revealed perioperative raised IOP was significantly associated with graft failure only in univariate analysis. Good IOP control is important to prolong corneal graft survival comparable to eyes with normal IOP.

The rate of infection following PKP in different countries ranges from $1.8 \%$ to as high as $11.9 \% .^{37,38}$ In this study, the rate of infection was $9.4 \%$ (eight eyes). We identified a higher corneal graft failure rate among eyes that encountered infection (three eyes, 37.5\%) compared to those without infections (ten eyes, $13.0 \%$ ), but statistical significance was marginally not met $(P=0.062)$. This could be due to our relatively small sample size. Nevertheless, this finding underscored the fact that aggressive and prompt control of infection is important to avoid corneal graft failure. Closer monitoring of elderly male patients regardless of the PKP indication is strongly advisable. The possibility of fungal infection should be ruled out in all cases.

We found there was no significant association between performing a concurrent procedure during PKP and corneal graft failure. Bersudsky et $\mathrm{al}^{39}$ showed that there was an increase of the corneal graft failure rate with simultaneous cataract surgery, but not with intraocular lens implant. In this study, the suture technique was not found to have a statistically significant association with corneal graft failure. This is in agreement with the findings reported by Inoue et al. ${ }^{35}$

The causes of corneal graft failure in our study were immune rejection in eight of eleven $(72.72 \%)$ eyes, raised IOP in two (18.18\%) eyes, and infection in one $(9.09 \%)$ eye. Data from the Australian Corneal Graft Registry 1990-1992 ${ }^{40}$ stated that the common reasons for failure of penetrating corneal graft were rejection (33\%), glaucoma $(11 \%)$, nonviral infections $(10 \%)$, endothelial cell failure $(8 \%)$, and herpetic infection $(7 \%)$. In our practice, the risk for herpetic keratitis recurrence, and thus corneal graft failure, was minimized by adopting a protocol using prophylactic perioperative oral valacyclovir and long-term postoperative topical ganciclovir, as previously described. ${ }^{26}$

In this series, statistically significant improvement of overall BSCVA from finger counting to Snellen acuity 20/60 following corneal transplantation was achieved. Individually, improvement in BSCVA was observed in 71 (83.5\%), unchanged in nine $(10.5 \%)$ and worsened in the remaining five $(5.9 \%)$ eyes. Wagoner et $\mathrm{al}^{22}$ reported overall improvement in vision in $82.4 \%$ of eyes, no change in $10.7 \%$ of the eyes, and deterioration in $6.9 \%$ of the eyes following adult PKP performed in a public health facility in Saudi Arabia. In our study, the proportions of eyes with postoperative BSCVA of $20 / 40$ or better and $20 / 80$ or better were $40.0 \%$ and $60.0 \%$, respectively. In general, postoperative vision improved significantly from preoperative vision following keratoplasty. Eyes that eventually had poor postoperative BSCVA were found to have concurrent ocular co-morbidity, such as advanced open-angle glaucoma.

\section{Conclusion}

The overall corneal graft survival is excellent in patients who are under close observation. Patient selection, proper donor corneal handling, and thorough preoperative and postoperative evaluation are crucial for successful corneal transplantation. While overall short-term corneal graft survival in PKP is excellent, long-term survival continues to be a topic of high interest. The high number of PKPs performed worldwide despite the emergence of various lamellar keratoplasty techniques underlines the importance of PKP as a vision-restorative procedure. Finally, with disruption of the geographic barriers in this global village, it was possible to obtain donor corneal tissues from eye banks in the US, underscoring international cooperation among the ophthalmic community. However, it is hoped that local 
donors will be widely available in the long run, as foreign donor tissues might be associated with antigen mismatches with local recipients.

\section{Acknowledgments}

This study was supported in part by funding from the Eye Center and The Eye Foundation for Research in Ophthalmology, Riyadh, Saudi Arabia.

\section{Disclosure}

The authors have no proprietary or commercial interest in any of the materials discussed in this study.

\section{References}

1. Armitage WJ, Tullo AB, Larkin DF. The first successful full-thickness corneal transplant: a commentary on Eduard Zirm's landmark paper of 1906. Br J Ophthalmol. 2006;90(10):1222-1223.

2. Moffatt SL, Cartwright VA, Stumpf TH. Centennial review of corneal transplantation. Clin Exper Ophthalmol. 2005;33(6):642-657.

3. World Health Organization. Second Global Consultation on Regulatory Requirements for Human Cells and Tissues for Transplantation: Towards Global Harmonization Through Graduated Standards. Geneva: WHO; 2006.

4. Guerin M, O' Connell E, Walsh C, Fulcher T. Visual outcomes and graft survival following corneal transplants: the need for an Irish National Corneal Transplant Registry. Ir J Med Sci. 2008;177(2):107-110.

5. Price MO, Thompson RW, Price FW. Risk factors for various causes of failure in initial corneal grafts. Arch Ophthalmol. 2003;121(8):1087-1092.

6. Thompson RW Jr, Price MO, Bowers PJ, Price FW Jr. Long-term graft survival after penetrating keratoplasty. Ophthalmology. 2003;110(7): 1396-1402.

7. Maier AK, Ozlügedik S, Rottler J, et al. Efficacy of postoperative immunosuppression after keratoplasty in herpetic keratitis. Cornea. 2011;30(12):1398-1405.

8. Tabbara KF. Pharmacologic strategies in the prevention and treatment of corneal transplant rejection. Int Ophthalmol. 2008;28(3):223-232.

9. Sloper CML, Powell RJ, Dua HS. Tacrolimus (FK506) in the management of high-risk corneal and limbal grafts. Ophthalmology. 2001;108(10):1838-1844.

10. Banerjee S, Dick AD. Recent developments in the pharmacological treatment and prevention of corneal graft rejection. Expert Opin Invest Drugs. 2003;12(1):29-37.

11. Reis A, Reinhard T. Current systemic immunosuppressive strategies in penetrating keratoplasty. In: Reinhard T, Larkin DFP, editors. Cornea and External Eye Disease. Heidelberg: Springer; 2006:109-122.

12. Al-Mezaine H, Wagoner MD. Repeat penetrating keratoplasty: indications, graft survival, and visual outcome. Br J Ophthalmol. 2006;90(3): 324-327.

13. Vanathi M, Sharma N, Sinha R, Tandon R, Titiyal JS, Vajpayee RB. Indications and outcome of repeat penetrating keratoplasty in India. BMC Ophthalmol. 2005;5:26.

14. Panda A, Vanathi M, Kumar A, Dash Y, Priya S. Corneal graft rejection. Surv Ophthalmol. 2007;52(4):375-396.

15. Boimer C, Lee K, Sharpen L, Mashour RS, Slomovic AR. Evolving surgical techniques of and indications for corneal transplantation in Ontario from 2000 to 2009. Can J Ophthalmol. 2011;46(4):360-366.

16. Módis L Jr, Szalai E, Facskó A, Fodor M, Komár T, Berta A. Corneal transplantation in Hungary (1946-2009). Clin Experiment Ophthalmol. 2011;39(6):520-525.

17. Wang J, Hasenfus A, Schirra F, Bohle RM, Seitz B, Szentmáry N. Changing indications for penetrating keratoplasty in Homburg/Saar from 2001 to 2010 - histopathology of 1,200 corneal buttons. Graefes Arch Clin Exp Ophthalmol. 2013;251(3):797-802.
18. Keenan TD, Carley F, Yeates D, et al. Trends in corneal graft surgery in the U K. Br J Ophthalmol. 2011;95(4):468-472.

19. Eye Bank Association of America. 2009 Eye Banking Statistical Report. Washington: EBAA; 2009.

20. Wagoner MD, Al-Ghamdi AH, Al-Rajhi AA. Bacterial keratitis after primary pediatric penetrating keratoplasty. Am J Ophthalmol. 2007;143(6):1045-1047.

21. Wagoner MD, Al-Swailem SA, Sutphin JE, Zimmerman MB. Bacterial keratitis after penetrating keratoplasty: incidence, microbiological profile, graft survival, and visual outcome. Ophthalmology. 2007;114(6):1073-1079.

22. Wagoner MD, Gonnah ES, Al-Towerki AE; King Khaled Eye Specialist Hospital Cornea Transplant Study Group. Outcome of primary adult penetrating keratoplasty in a Saudi Arabian population. Cornea. 2009;28(8):882-890.

23. Wagoner MD, Ba-Abbad R, Sutphin JE, Zimmerman MB. Corneal transplant survival after onset of severe endothelial rejection. Ophthalmology. 2007;114(9):1630-1636.

24. Wagoner M, Gonnah ES, Al-Towerki AE. Outcome of primary adult optical penetrating keratoplasty with imported donor corneas. Int Ophthalmol. 2010;30(2):127-136.

25. Bukhari A, Ajlan R, Alsaggaf H. Prevalence of dry eye in the normal population in Jeddah, Saudi Arabia. Orbit. 2009;28(6):392-397.

26. Tabbara KF. Treatment of herpetic keratitis. Ophthalmology. 2005;112(9): 1640.

27. Wagoner MD, Ba-Abbad R, Al-Mohaimeed M, Al-Swailem S, Zimmerman MB; King Khaled Eye Specialist Hospital Corneal Transplant Study Group. Postoperative complications after primary adult optical penetrating keratoplasty: prevalence and impact on graft survival. Cornea. 2009;28(4):385-394.

28. Tan DT, Janardhanan P, Zhou H, et al. Penetrating keratoplasty in Asian eyes: the Singapore Corneal Transplant Study. Ophthalmology. 2008;115(6):975-982.

29. Fasolo A, Frigo AC, Böhm E, et al. The CORTES study: corneal transplant indications and graft survival in an Italian cohort of patients. Cornea. 2006;25(5):507-515.

30. Sheldon CA, McCarthy JM, White VA. Correlation of clinical and pathologic diagnoses of corneal disease in penetrating keratoplasties in Vancouver: a 10-year review. Can J Ophthalmol. 2012;47(1):5-10.

31. Nicholls SM, Bradley BB, Easty DL. Effect of mismatches for major histocompatibility complex and minor antigens on corneal graft rejection. Invest Ophthalmol Visl Sci. 1991;32(10):2729-2734.

32. Fasolo A, Capuzzo C, Fornea M, et al. Risk factors for graft failure after penetrating keratoplasty: 5-year follow-up from the corneal transplant epidemiological study. Cornea. 2011;30(12):1328-1335.

33. Al-Towerki AE, Gonnah el-S, Al-Rajhi A, Wagoner MD. Changing indications for corneal transplantation at the King Khaled Eye Specialist Hospital (1983-2002). Cornea. 2004;23(6):584-588.

34. Yalniz-Akkaya Z, Burcu Nurozler A, Yildiz E, Onat M, Budak K, Duman S. Repeat penetrating keratoplasty: indications and prognosis, 1995-2005. Eur J Ophthalmol. 2009;19(3):362-368.

35. Inoue $\mathrm{K}$, Amano S, Oshika T, Tsuru T. Risk factors for corneal graft failure and rejection in penetrating keratoplasty. Acta Ophthalmol Scand. 2001;79(3):251-255.

36. Anshu A, Lim LS, Htoon HM, Tan DT. Postoperative risk factors influencing corneal graft survival in the Singapore corneal transplant study. Am J Ophthalmol. 2011;151(3):442-448.

37. Vajpayee RB, Sharma N, Sinha R, Agarwal T, Singhvi A. Infectious keratitis following keratoplasty. Surv Ophthalmol. 2007;52(1):1-12. Review.

38. Sellami D, Abid S, Bouaouaja G, et al. Epidemiology and risk factors for corneal graft rejection. Transplant Proc. 2007;39(8):2609-2611.

39. Bersudsky VU, Rehany U, Rumelt S. Risk factors for failure of simultaneous penetrating keratoplasty and cataract extraction. J Cataract Refract Surg. 2004;30(9):1940-1947.

40. [No authors listed]. The Australian Corneal Graft Registry. 1990 to 1992 report. Aust N Z J Ophthalmol. 1993;21 Suppl 2:1-48. 


\section{Publish your work in this journal}

Clinical Ophthalmology is an international, peer-reviewed journal covering all subspecialties within ophthalmology. Key topics include: Optometry; Visual science; Pharmacology and drug therapy in eye diseases; Basic Sciences; Primary and Secondary eye care; Patient Safety and Quality of Care Improvements. This journal is indexed on
PubMed Central and CAS, and is the official journal of The Society of Clinical Ophthalmology (SCO). The manuscript management system is completely online and includes a very quick and fair peer-review system, which is all easy to use. Visit http://www.dovepress.com/ testimonials.php to read real quotes from published authors. 